\title{
MENUJU PENELITIAN PENDIDIKAN YANG SADAR KONTEKS
}

\author{
Habibi \\ FKIP, Universitas Wiraraja
}

\begin{abstract}
ABSTRAK
Penelitian pendidikan merupakan jantung dari upaya peningkatan kualitas proses pendidikan. Tulisan ini menjelaskan bagaimana karakter yang dimiliki oleh penelitian dalam bidang pendidikan dan perkembangannya yang bersifat integratif untuk dapat benarbenar menyesuaikan diri dengan kompleksitas realita sosial yang menjadi konteks dari proses pendidikan. Juga akan dianalisis bagaimana kondisi penelitian pendidikan di Indonesia yang masih banyak diliputi permasalahan, terutama pada aspek theory oriented.
\end{abstract}

Kata Kunci: Penelitian Pendidikan, integratif, theory oriented

\section{Pendahuluan}

Pendidikan merupakan salah satu amanat pokok Undang-undang Dasar atas berdirinya Republik Indonesia. Sebagai proses yang akan melahirkan generasi penerus bangsa ke depan, tentunya pendidikan menjadi prioritas yang senantiasa harus mendapat dorongan dan dukungan untuk menjadi semakin baik. Melalui peningkatan dan pengembangan kualitas itulah diharapkan cita-cita luhur dari keberadaan bangsa ini dapat dirasakan oleh setiap elemen masyarakat.

Pendidikan adalah suatu bentuk institusi yang dinamis dan unik. Institusi ini ibaratnya sebuah mesin otomatis, yang tidak hanya dapat bekerja untuk tujuan tertentu, melainkan juga dapat menghasilkan output yang berfungsi untuk memperbaiki dan mengembangkan dirinya sendiri. Melalui berbagai aktivitas ilmiah (penelitian), para praktisi pendidikan dapat mengonstruk ilmu, menganalisis diri dan mengembangkan teknik-teknik tertentu untuk mengembangkan kualitas dirinya sendiri. Oleh karena itulah penelitian menjadi jantung dari institusi pendidikan.

\section{Penelitian dalam Pendidikan}

Educational research is the application of the scientific approach to the study of educational problems.

Educational research is
the way in which
people acquire
dependable and useful
information about the
educative process.
Educators usually
conduct research to
find a solution to some
problem or to gain
insight into an issue
they do not understand
(Ary, Jacobs \&
Sorensen, 2010)

Berdasarkan pernyataan Ary dan koleganya, secara ringkas dapat dipahami bahwa penelitian pendidikan memiliki dua fungsi utama yaitu fungsi eksploratif dimana berbagai proses yang terjadi dalam dunia pendidikan didalami dan dijelaskan secara rasional dan sederhana. Kedua adalah fungsi solutif, yaitu menghasilkan hal-hal nyata yang dapat mengatasi berbagai permasalahan yang terjadi dalam proses pendidikan.

Kedua fungsi utama tersebut, walaupun tidak benar-benar absolut, membagi penelitian pendidikan menjadi dua pendekatan utama yaitu pendekatan kualitatif fenomenologis dan pendekatan kuantitatif positivis. Dalam pendekatan yang pertama, penelitian benar-benar diarahkan untuk mendalami kenyataan yang terjadi dengan berbagai penyebab 
yang seringkali tidak dapat terlihat secara langsung dan mudah. Adapun pendekatan kedua lebih terfokus pada upaya untuk menjelaskan permasalahan dan mencari solusi-solusi bagi permasalahan tersebut secara sistematis dan terukur. Dalam pendekatan kuantitatif, prediksi hasil yang akan diperoleh akan sebuah perlakuan yang terukur dan obyektif benar-benar menjadi fokus pelaksanaannya.

Lodico, Spaulding \& Voegtle (2006) menambahkan perspektif dari implementasi penelitian dalam dunia pendidikan. Menurut mereka secara lebih mendasar penelitian pendidikan diterapkan berdasarkan empat paradigma besar yaitu scientific realism, Social constructivism, advocacy liberatory dan pragmatism. Dalam paradigma scientific realism penelitian benar-benar harus bersifat obyektif agar dapat menghasilkan penjelasan ataupun solusi atas permasalahan. Paradigma Social constructivism lebih memperhatikan kontekstualitas data agar teori atau solusi yang dihasilkan benar-benar cocok untuk kondisi permasalahan.
Paradigma advocacy liberatory lebih jauh lagi memahami nilai dan kondisi masyarakat (konteks) tidak hanya sebagai aspek yang harus diperhatikan dalam penelitian, melainkan juga menjadi tujuan utama. Dalam paradigma yang ketiga ini penelitian dianggap memiliki kewajiban ilmiah untuk memberdayakan masyarakat, terutama masyarakat yang tertindas dan terpinggirkan. Paradigma yang keempat yaitu pragmatism lebih terfokus pada upaya untuk meningkatkan kualitas pendidikan dengan berbagai cara dan jenis penelitian. Tujuan utama penelitian dalam paradigma yang terakhir ini adalah hasil yang nyata. Untuk itu konteks dan kondisi partisipan harus diperhatikan dan mereka seyogyanya juga terlibat dalam penelitian untuk memastikan hasil yang benar. Lebih lengkapnya, perbedaan keempat paradima tersebut dapat dilihat pada Tabel 1. Jika digolongkan berdasarkan orientasinya maka paradigma satu dan dua lebih berorientasi pada pembentukan pengetahuan sedangkan paradigma tiga dan empat lebih berorientasi pada hasil implementasinya.

Tabel 1. Empat Paradigma dalam Penelitian Pendidikan menurut Lodico, Spaulding \& Voegtle (2006)

\begin{tabular}{|c|c|c|}
\hline & Scientific Realism & Social Constructivism \\
\hline $\begin{array}{l}\text { Knowledge-oriented } \\
\text { approaches }\end{array}$ & $\begin{array}{l}\text { - Research aims to describe an } \\
\text { objective reality that most or } \\
\text { all people would agree is real } \\
\text { - Educational settings and } \\
\text { problems can be studied by } \\
\text { empirical analysis of compo- } \\
\text { nent parts } \\
\text { - Research should be value-free } \\
\text { - Researchers should be de- } \\
\text { tached from participants and } \\
\text { strive to be objective } \\
\text { - Theories and hypotheses are } \\
\text { formed and then confirmed } \\
\text { or disconfirmed through } \\
\text { collection of data }\end{array}$ & $\begin{array}{l}\text { - Reality is historically and cul- } \\
\text { turally constructed so there } \\
\text { are multiple possible realities } \\
\text { - Educational settings and } \\
\text { problems must be understood } \\
\text { as complex wholes } \\
\text { - Researchers must continually } \\
\text { strive to be aware of and con- } \\
\text { trol their values } \\
\text { - Researchers should become } \\
\text { actively involved with partici- } \\
\text { pants in order to understand } \\
\text { their perspectives } \\
\text { - Theories and hypotheses } \\
\text { are generated during data } \\
\text { collection and achieve } \\
\text { meaning through human } \\
\text { interactions }\end{array}$ \\
\hline
\end{tabular}




\begin{tabular}{|c|c|c|}
\hline & Advocacy-Liberatory & Pragmatism \\
\hline $\begin{array}{l}\text { Action-oriented } \\
\text { approaches }\end{array}$ & $\begin{array}{l}\text { - Reality is socially constructed } \\
\text { and influenced by social, po- } \\
\text { litical, and cultural inequalities } \\
\text { - Although qualitative methods } \\
\text { are preferred, educational } \\
\text { settings and problems can } \\
\text { be studied using any meth- } \\
\text { ods that truly represent } \\
\text { the experiences of the } \\
\text { participants } \\
\text { - Research must be based in } \\
\text { values and should empower } \\
\text { marginalized groups to im- } \\
\text { prove their lives } \\
\text { - Researchers should collabo- } \\
\text { rate with participants as equal } \\
\text { partners } \\
\text { - Theories and hypotheses } \\
\text { should provide action plans } \\
\text { to achieve a better life }\end{array}$ & $\begin{array}{l}\text { - The immediate reality of } \\
\text { solving educational problems } \\
\text { should be the focus of edu- } \\
\text { cational research } \\
\text { - Educational settings and } \\
\text { problems can be studied } \\
\text { using any method that accu- } \\
\text { rately describes or solves a } \\
\text { problem } \\
\text { - Research should strive to } \\
\text { find ways to make education } \\
\text { better } \\
\text { - Researchers should collabo- } \\
\text { rate with participants to fully } \\
\text { understand what works } \\
\text { - Theories and hypotheses } \\
\text { are useful tools in helping to } \\
\text { improve education }\end{array}$ \\
\hline
\end{tabular}

Perbedaan pendekatan ataupun paradigma dasar yang melandasi setiap penelitian yang dilakukan dalam dunia pendidikan, jika kita mau melakukan refleksi secara lebih jauh sebenarnya bersifat saling melengkapi dan menyempurnakan. Aspek-aspek yang lebih diutamakan dalam satu pendekatan atau paradigma dasar membuatnya memiliki kelemahan pada aspek yang lain.

\section{Perkembangan Integratif Penelitian dalam Pendidikan}

Sejak Revolusi ilmiah dan Industri yang berlangsung di Eropa, ilmu pengetahuan diyakini mampu menjawab berbagai permasalahan manusia secara sistematis, rasional dan obyektif. Pendekatan kuantitatif positivis menjadi satu-satunya pendekatan penelitian yang diakui. Orientasi utama penelitian adalah untuk mengembangkan pengetahuan atau teknologi. Hal ini menjadikan penelitian lebih cenderung untuk bahan konsumsi kaum intelektual belaka.

Perubahan mulai pesat terjadi ketika pandangan tokoh pragmatis Amerika John Dewey pada awal abad 20 banyak digunakan oleh para praktisi dan peneliti pendidikan di dunia. Pemikiran Dewey mengenai pendidikan salah satunya diungkapkan oleh Santrock (2011) berikut,

Dewey give the idea that education should focus on the whole child and emphasize the child's adaptation to the environment. Dewey reasoned that children should not be just narrowly educated in academic topics but should learn how to think and adapt to a world outside school.

Paradigma Pendidikan yang sebelumnya memperlakukan siswa sebagai obyek yang pasif dan dapat memberikan data-data obyektif dan terukur secara pasti berubah menjadi lebih memperlakukan siswa sebagai pribadi yang aktif dan memiliki karakter otonom. Akibatnya penelitian dalam dunia pendidikan menjadi lebih peka terhadap partisipan dan juga konteks kehidupan siswa. 
Perubahan besar juga dibawa oleh Paulo Freire dari Brazil yang memperjuangkan pendidikan untuk kaum tertindas. Arah pendidikan menurutnya harus membawa siswa kepada kesadaran untuk hidup sebagai manusia yang bebas dan bertanggung jawab. Baginya para pejuang pendidikan tidak boleh hanya terfokus pada teori-teori yang dihasilkan dan diajarkan pada siswa melainkan juga membangkitkan kesadaran dalam diri siswa itu sendiri.

Ever since he wrote his
thesis to become
Professor of History
and the Philosophy of
Education at the
University of Recife,
Paulo Freire has
referred to John
Dewey, quoting his
work Democracy and
Education, published in
Brazil in 1936. It was
Anisio Teixeira, who
introduced Dewey's
work into Brazil. Paulo
Freire was a great
admirer of the
pedagogy of Anisio
Teixeira, of whose
work he considered
himself a disciple and
with whom he agreed
in his criticism of
excessive centralism,
connected toritarianism and
authoritariantion
elitism, ine Brazilian
educational system
(Gadotti, 1994).

Penjelasan Gadotti di atas menunjukkan bahwa Freire merupakan salah satu pengikut pemikiran Dewey mengenai pentingnya pendidikan untuk mengajarkan dan memperjuangkan kepentingan setiap orang, terutama masyarakat lemah. Dalam proyek pendidikan untuk penyadaran masyarakat ini maka Freire menjadi sadar bahwa peserta didik tidak boleh hanya menjadi obyek tetapi juga terutama harus menjadi subyek yang aktif untuk memikirkan masa depannya secara bebas. Dalam prinsip education of liberation tersebut karakter penelitian pendidikan lebih terpusat untuk membangun kesadaran peserta didik. Kedudukan peneliti dan subyek yang ditelitinya menjadi sejajar.

Perkembangan teknologi informasi semakin memperkuat interaksi antar budaya dan pemikiran yang berbeda. Interaksi tersebut salah satu dampaknya adalah pada kesadaran para praktisi pendidikan untuk melihat kerumitan berbagai aspek dalam hidup manusia yang menjadi obyek dari pendidikan. Untuk itu pendekatan-pendekatan tunggal ataupun sikap menutup diri terhadap sudut pandang yang berbeda semakin ditinggalkan. Integrasi metode dan pendekatan dalam penelitian semakin banyak dipilih untuk hasil yang lebih dekat dengan realitas hidup yang sesungguhnya.

Pendekatan kuantitatif dan kualitatif telah memiliki kedudukan sejajar bahkan dianggap dapat saling melengkapi. Demikian pula dengan empat paradigma (filosofi) yang mendasari aktivitas penelitian, semakin tidak hanya menggunakan satu jenis paradigma saja melainkan integrasi diantaranya. Era postmodern memberi kesadaran kepada manusia akan keterbatasannya untuk memahami kompleksitas fenomena kehidupan atau sosial hanya melalui kacamata positivistik. Kita semakin sadar bahwa hanya dengan multipendekatan seja kompleksitas tersebut akan dapat terurai.

Pada awal abad 21, metode campuran (mix method) yang memadukan pendekatan kuantitatif dan kualitatif dalam satu proses penelitian mulai banyak digunakan oleh para peneliti pendidikan. Tidak hanya itu, penelitian tindakan yang sebelumnya dianggap tidak memenuhi syarat dasar keilmuan (validitas dan 
reliabilitas data yang diperoleh) kini semakin banyak diakui penggunaannya secara ilmiah berdasarkan nilai kemanfaatan dan paradigma bahwa guru seharusnya dapat menjadi aktor utama yang berpartisipasi aktif dalam mengembangkan kualitas pendidikan. Koshy (2005) memberi penjelasan mengenai bagaimana penelitian tindakan dapat memenuhi standar validitas ilmiah.

The work is located
within one's context
and acknowledged as
such.ring on national
drawing
samples is not a
requirement. By using
a variety of research
methods used in
traditional research,
the action researcher
can carry out the work
keeping torstrict
standards. Sharing
data with critical
friends and
triangulation would
ensure that the quality
of what is gathered is
robust and without
bias.

Berdasarkan ungkapan Koshy di atas terdapat gambaran bahwa penelitian tindakan semakin dirancang untuk memenuhi kaidah keilmuan. Validitas dapat dicapai melalui metode-metode yang bervariasi seperti pada jenis-jenis penelitian tradisional yang telah ada. Selain itu metode triangulasi dan sharing dengan teman-teman sejawat seperti yang dilakukan oleh pendekatan fenomenologis dapat digunakan untuk semakin meningkatkan kredibilitas data hasil penelitian.

\section{Penelitian Pendidikan di Indonesia}

Indonesia merupakan salah satu negara berkembang yang juga memiliki fokus untuk meningkatkan kualitas pendidikannya melalui cara-cara ilmiah. Oleh karena itulah pada setiap jenjang pendidikan tinggi mulai level sarjana hingga doktoral, penelitian menjadi tugas akhir yang harus dilalui untuk syarat kelulusan. Selain itu salah satu tugas wajib dari seorang dosen ataupun guru adalah penelitian. Bedanya pada dosen penelitian yang dilakukan bersifat lebih luas meliputi berbagai metode dan pendekatan, sedangkan untuk seorang guru kewajiban penelitian hanya terfokus pada penelitian tindakan kelas.

Data mengenai kondisi penelitian di Indonesia secara umum masih belum menggembirakan. Berdasarkan data lembaga SCImago yang dirilis tahun 2013, indonesia selama 16 tahun (19962011) telah menghasilkan 16.139 penelitian. Peringkat Indonesia dalam produktivitas penelitian di dunia adalah peringkat 63. Jika dibandingkan dengan beberapa negara tetangga yang jauh lebih kecil seperti Singapura (peringkat 32 dengan 126.881 penelitian), Malaysia (peringkat 42 dengan 75.530 penelitian) dan Thailand (peringkat 43 dengan 69.637 penelitian) maka kita dapat mengetahui bahwa ketertinggalan dunia penelitian di Indonesia cukup besar.

Selama 16 tahun data produktivitas penelitian di Indoensia sebenarnya selalu mengalami peningkatan (lihat Tabel 2), namun masih kalah jauh dengan peningkatan yang dialami oleh negara-negara tetangga yang telah disebut di atas. Hal ini kemungkinan disebabkan dengan semakin produktifnya suatu negara untuk menghasilkan penelitian maka akan berimbas pada atmosfer ilmiah negara tersebut sehingga peningkatan jumlah penelitian di tahun-tahun berikutnya juga akan bertambah besar. Dengan demikian upaya kita untuk meningkatkan kualitas penelitian masih perlu untuk benar-benar dipacu. 
Tabel 2. Data Jumlah Penelitian di Indonesia Tahun 1996-2011 Berdasarkan Survei SCImago (rilis 2013)

\begin{tabular}{|c|c|c|c|c|c|c|c|c|c|c|c|}
\hline & Documents & $\begin{array}{c}\text { Citable } \\
\text { Documents }\end{array}$ & Cites & $\begin{array}{l}\text { Self } \\
\text { Cites }\end{array}$ & $\begin{array}{c}\text { Cites } \\
\text { per Doc. }\end{array}$ & $\begin{array}{l}\text { Self Cites } \\
\text { per Doc. }\end{array}$ & $\begin{array}{l}\text { Cited } \\
\text { Docs. }\end{array}$ & $\begin{array}{l}\text { Uncited } \\
\text { Docs. }\end{array}$ & $\begin{array}{l}\% \text { International } \\
\text { Collaboration }\end{array}$ & $\begin{array}{c}\% \\
\text { Region }\end{array}$ & $\begin{array}{c}\% \\
\text { World }\end{array}$ \\
\hline 1996 & 513 & 506 & 8.150 & 702 & 15,89 & 1,37 & 423 & 90 & 74,66 & 0,32 & 0,05 \\
\hline 1997 & 539 & 537 & 8.075 & 781 & 14,98 & 1,45 & 464 & 75 & 76,44 & 0,31 & 0,05 \\
\hline 1998 & 500 & 490 & 7.333 & 612 & 14,67 & 1,22 & 420 & 80 & 75,20 & 0,28 & 0,04 \\
\hline 1999 & 541 & 535 & 8.047 & 834 & 14,87 & 1,54 & 473 & 68 & 72,83 & 0,28 & 0,05 \\
\hline 2000 & 581 & 574 & 10.105 & 1.018 & 17,39 & 1,75 & 498 & 83 & 73,49 & 0,29 & 0,05 \\
\hline 2001 & 543 & 535 & 7.943 & 750 & 14,63 & 1,38 & 453 & 90 & 70,53 & 0,25 & 0,04 \\
\hline 2002 & 516 & 502 & 7.476 & 659 & 14,49 & 1,28 & 430 & 86 & 69,77 & 0,23 & 0,04 \\
\hline 2003 & 677 & 660 & 8.582 & 897 & 12,68 & 1,32 & 550 & 127 & 79,47 & 0,26 & 0,05 \\
\hline 2004 & 779 & 765 & 9.570 & 1.002 & 12,28 & 1,29 & 629 & 150 & 80,87 & 0,26 & 0,05 \\
\hline 2005 & 956 & 939 & 10.067 & 1.094 & 10,53 & 1,14 & 713 & 243 & 77,20 & 0,25 & 0,05 \\
\hline 2006 & 1.042 & 1.022 & 10.250 & 1.091 & 9,84 & 1,05 & 809 & 233 & 78,41 & 0,24 & 0,06 \\
\hline 2007 & 1.113 & 1.084 & 8.536 & 1.135 & 7,67 & 1,02 & 794 & 319 & 75,20 & 0,24 & 0,06 \\
\hline 2008 & 1.250 & 1.222 & 8.118 & 1.065 & 6,49 & 0,85 & 860 & 390 & 75,04 & 0,24 & 0,06 \\
\hline 2009 & 1.705 & 1.669 & 7.846 & 1.005 & 4,60 & 0,59 & 1.035 & 670 & 68,68 & 0,29 & 0,08 \\
\hline 2010 & 2.143 & 2.088 & 4.172 & 759 & 1,95 & 0,35 & 1.009 & 1.134 & 65,75 & 0,33 & 0,10 \\
\hline 2011 & 2.741 & 2.651 & 1.575 & 315 & 0,57 & 0,11 & 644 & 2.097 & 56,88 & 0,38 & 0,12 \\
\hline
\end{tabular}

Peningkatan jumlah penelitian juga harus diimbangi dengan peningkatan kualitas penelitian yang dilakukan. Seperti yang telah dibahas pada subbab sebelumnya mengenai pergeseran orientasi pada era postmodern yang semakin mencoba untuk mendekati realitas secara utuh dan mendalam, maka demikian pula seharusnya dengan kondisi penelitian kita. Penelitian pendidikan yang sadar kompleksitas fenomena sosial seharusnya penjadi tujuan kita saat ini.

Sejak tahun 80-an Suriasumantri (1984) telah mengingatkan bahwa keadaan masyarakat kita masih jauh dari tahap masyarakat yang berorientasi kepada ilmu. Bahkan dalam masyarakat yang telah terdidik pun ilmu dikatakan masih merupakan koleksi teori-teori yang bersifat akademik dan sama sekali tidak fungsional dalam kehidupan sehari-hari. Begitu pula dengan banyak penelitian yang dilakukan, sifatnya cenderung hanya memberi tambahan teori dan pengetahuan.

Penelitian yang hanya bertujuan untuk menambah wawasan (tujuan pengetahuan) untuk saat ini masih mendominasi penelitian pendidikan yang kita lakukan. Hal ini mengakibatkan ketidakpercayaan publik terutama institusi pendidikan untuk benar-benar menggunakan hasil-hasil penelitian tersebut. Kondisi ini diperparah oleh karakter pemerintahan yang masih menempatkan kepentingan politik di atas pertimbangan-pertimbangan ilmiah dalam membuat kebijakan-kebijakan bahkan untuk dunia pendidikan. Penghalang yang paling besar adalah tingginya budaya korupsi yang berujung pada kemalasan dan tidak produktifnya masyarakat.

Aspek terakhir yang menjadi gambaran dari penelitian pendidikan yang dilakukan di Indonesia adalah jarak antara ilmuwan dan praktisi pendidikan. Jarak ini didukung pula oleh tidak adanya kerja sama yang baik antara sekolah dengan lembaga penelitian terutama di Perguruan Tinggi. Tidak terbukanya sekolah menyebabkan penelitian yang dilakukan seringkali tidak menyentuh permasalahan sebenarnya sehingga jauh dari efek perbaikan, sebaliknya Perguruan Tinggi yang kurang membangun relasi dekat dengan sekolah menjadi terbiasa dengan karakter theory oriented. 
Efek dari jarak antara ilmuwan dan praktisi pendidikan ini juga terlihat pada perubahan-perubahan yang dilakukan pada kurikulum umumnya kurang memberi dampak perubahan besar bagi proses pendidikan di lapangan. Ilmuwan yang harusnya melakukan upaya-upaya ilmiah untuk menerjemahkan kurikulum dan juga menganalisis permasalahan yang terjadi di lapangan terkait dengan perubahan kurikulum tidak pernah benar-benar dapat melaksanakannya dengan baik.

Davis (2008) menyebutkan beberapa cara yang dapat dilakukan untuk mengurangi dan menghilangkan jarak antara peneliti dan praktisi dalam pendidikan, di antara sebagai berikut:

1. Lembaga Pendidikan Tinggi penghasil praktisi dan sekaligus peneliti harus memperbaiki kualitas diri agar dapat menghasilkan praktisi dan peneliti yang menyadari pentingnya integrasi tersebut.

2. Menciptakan banyak ruang-ruang pertemuan antara peneliti dan praktisi terutama melalui diseminasi ilmiah.

3. Peningkatan kualitas perpustakaan sekolah yang tidak hanya berisi informasi ilmiah untuk siswa melainkan juga untuk para guru.

4. Penghargaan bagi para guru yang mau melakukan penelitian tindakan kelas dan juga mempublikasikannya tidak hanya kepada praktisi lain tetapi juga para peneliti di Perguruan Tinggi.

5. Jurnal-jurnal yang bermutu sebaiknya memberi ruang lebih banyak lagi bagi penelitian tindakan kelas yang selama ini masih dianggap sebagai bentuk penelitian yang kurang standar.

6. Ilmuwan di bidang pendidikan harus berupaya lebih dekat dengan dunia pendidikan secara nyata di sekolah.
DAFTAR PUSTAKA

Ary, D. Jacobs, L.C. \& Sorensen, C. 2010. Introduction to Research in Education. Belmont: Wadsworth

Davis, S.H. 2008. Research and Practice in Education, The Search for Common Ground. Maryland: Rowman and Littlefield Education

Gadotti, Moacir. 1994. Reading Paulo Freire, His Life and Work. New York: State University

Lodico, M.G. Spaulding, D.T. \& Voegtl, K.H. 2006. Methods an Educational Research, from Theory to Practice. San Francisco: Josse Bass

Schunk, D.H. 2012. Learning Theories, an Educational Perspectives. Boston: Pearson Education Inc.

SCImago. (2007). SJR - SCImago Journal \& Country Rank. Retrieved June 22, 2013, from http://www.scimagojr.com

Suriasumantri, J.S. 1984. Filsafat Ilmu, Sebuah Pengantar. Jakarta: Pustaka Sinar Harapan 